\title{
Stiffness variation of porous titanium developed using space holder method
}

\author{
L. Reig*1, V. Amigó ${ }^{2}$, D. Busquets ${ }^{2}$ and J. A. Calero ${ }^{3}$
}

The excellent properties of Ti have resulted in its generalised use for bone implants. However, Ti is very stiff in comparison with human cortical bone, and this creates problems of bone weakening and loosening of the implant. This article discusses the mechanical properties (flexural and compressive strength, and stiffness) of porous Ti-6Al-4V specimens developed using the space holder method. These properties are examined relative to the production process parameters: compacting pressure and sintering time, as well as temperature, and the addition of spacer and its particle size. It is seen that when spacer is added, compressive strength decreases with the application of compacting pressure and that these are the most influential parameters. The developed pieces show a closed and unconnected porosity. Small additions of spacer (25 vol.-\%) reduce stiffness to around half of that shown by the solid material, and the resulting pieces are strong enough to be used as bone substitute.

Keywords: Porous Ti-6Al-4V, Space holder, Bending strength, Compression strength, Stiffness

\section{Introduction}

The excellent properties of Ti make it an ideal candidate for use as a bone graft. However, production is difficult because vacuum techniques are required to minimise reactivity with gases in the furnace. Moreover, although its stiffness (100$110 \mathrm{GPa})^{1,2}$ is small when compared to other implant materials, it is still higher than human cortical bone (10$40 \mathrm{GPa}),{ }^{1,3}$ and this leads to bone weakening and loosening of the implant ${ }^{4}$ due to the stress shielding phenomenon.

Among the various methods for reducing the stiffness of the implant, ${ }^{5-8}$ the development of porous pieces with the spacer method is one of the most widely used., ${ }^{9,10}$ Porosity is generated by removing the spacer that was mixed together and compacted with the base material. The aim of this work is to develop specimens of porous $\mathrm{Ti}-6 \mathrm{Al}-4 \mathrm{~V}$ using the spacer method and measure the change in resistance to bending, compression and stiffness, as influenced by the process parameters (compacting pressure, sintering time and temperature, addition of spacer and particle size).

\section{Experimental}

\section{Development of porous specimens using spacer method}

Specimens were developed following procedures described in previous works. ${ }^{11} \mathrm{Ti}$ alloy selected for this

\footnotetext{
1Departamento de Ingeniería Mecánica y Construcción, Universidad Jaime I de Castellón. Av. de Vicent Sos Baynat, s/n, 12071 Castelló de la Plana, Spain

${ }^{2}$ Departamento de Ingeniería Mecánica y de Materiales, Universidad Politécnica de Valencia, Camino de Vera s/n, 46022 Valencia, Spain

${ }^{3}$ Aleaciones de Metales Sinterizados SA, San Vicenç dels Horts, Barcelona, Spain

*Corresponding author, email Ireig@emc.uji.es
}

research was $\mathrm{Ti}-6 \mathrm{Al}-4 \mathrm{~V}$ powder produced by hydration-dehydration. The powder was supplied by Se-Jong Materials (Inchon, South Korea), which also provided its chemical composition ${ }^{11}$ and sieve analysis $(<45 \mu \mathrm{m})$. Ammonium bicarbonate was used as a spacer, and the bicarbonate was ground and sieved to three different sizes $(125-250,250-500$ and $500-1000 \mu \mathrm{m})$. Given the irregular morphology of both materials, ${ }^{11}$ the strength acquired after compacting was sufficient to enable manipulation to remove the spacer.

After mixing the Ti-6Al-4V and ammonium bicarbonate (volume per cent Ti-6Al-4V/Esp: 100/0, 75/25, 60/40, $45 / 55$ and $30 / 70$ ), the mixture was compacted to 100,200 and $300 \mathrm{MPa}$ in a 100 ton uniaxial hydraulic press at a rate of $3000 \mathrm{~N} \mathrm{~s}^{-1}$ after contact with the mix. For each combination of variables, three compression samples $(\varnothing=25 \mathrm{~mm}, \quad h \approx 27 \mathrm{~mm})$ and five bending samples $(32 \times 12 \times 6 \mathrm{~mm})$ were produced.

After the spacer was removed, the samples were sintered in a vacuum at temperatures of $1300 \pm 25^{\circ} \mathrm{C}$ for periods of 1,2 and $4 \mathrm{~h}^{11}$

\section{Analysis of porous specimens}

After metallographic preparation, the samples were examined under a Nikon SMZ800 stereo optical microscope, a MicroPhoto Nikon FX microscope and a JEOL JSM6300 scanning electron microscope equipped with an Oxford Instruments EDX 6508 detector. The density $\rho^{*}$ and porosity of the sintered material were determined by measuring the mass and dimensions. The solid density $\rho_{\mathrm{S}}$ of $4.42 \mathrm{~g} \mathrm{~cm}^{-3}$ was used to measure the relative density $\left(\rho_{\mathrm{r}}=\rho^{*} / \rho_{\mathrm{S}}\right){ }^{2}$

Strength and flexural stiffness were measured with the three point bend test, following ASTM E290-97a (ISO 3325:2000) and applied in an Instron 4204 machine with

(C) 2010 Institute of Materials, Minerals and Mining Published by Maney on behalf of the Institute

Received 8 January 2010; accepted 15 March 2010

DOI 10.1179/003258910X12707304455068 


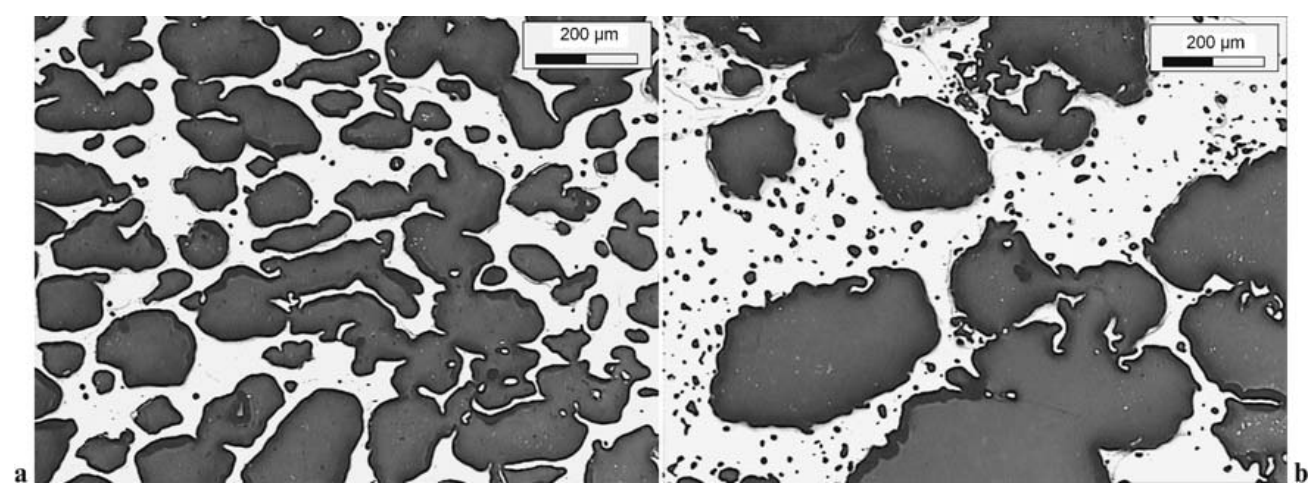

a 125-250 $\mu \mathrm{m} ; b$ 500-1000 $\mu \mathrm{m}$

1 Micrograph of porous pieces developed with different spacer particle sizes

a crosshead speed of $0.5 \mathrm{~mm} \mathrm{~min}^{-1}$. Flexural stiffness $E_{\mathrm{FP}}^{*}$ was measured using the slope of the stress-strain $\sigma-$ $\varepsilon$ curve and maximum deflection $E_{\mathrm{FF}}^{*}$ using the Young's modulus formula. ${ }^{9}$

The compression test was performed in accordance with ASTM E9-89a, in an Instron A1340-1006, with up to $600 \mathrm{KN}$ of static load and a load speed of $0.5 \mathrm{~mm} \mathrm{~min}^{-1}$ until achieving a relative strain of $7 \mathrm{~mm}$. The compressive stiffness $E_{\mathrm{C}}^{*}$ was measured by determining the slope of the stress-strain curve.

The relative stiffness $\left(E_{\mathrm{r}}=E^{*} / E_{\mathrm{S}}\right)$ was calculated for each of the measuring methods by taking the rigidity of the solid $E_{\mathrm{S}}$ as evidenced by the samples without spacers that were compacted at the same pressure $\left(E_{\mathrm{SFF}}, E_{\mathrm{SFP}}\right.$ and $\left.E_{\mathrm{SC}}\right)$. Owing to the localised plasticisation that occurs in porous metals in the apparently elastic region of the stress-strain curve, ${ }^{12}$ we will refer to 'rigidity' rather than the 'modulus of elasticity'.

\section{Results and discussion}

\section{Porosity and pore size}

The produced porous specimens have a dense outer skin, with a degree of porosity that depends primarily on the volume of spacer. Unlike the TiCP porous specimens produced in a previous research, in which compaction was performed manually, ${ }^{9}$ the porosity of the Ti-6Al$4 \mathrm{~V}$ specimens increased by between 10 and $14 \%$ after the addition of spacer. ${ }^{11}$ This is due to the quickness of the compaction applied, which produces greater elastic recovery in the powder.

Figure 1 shows the difference between micro- and macropores. While the former are the product of the powder metallurgical process and reduced compacting pressures, the latter result from the evaporation of bicarbonate. Although spacer particles tend to coalesce, connections do not develop between all the particles and so the porosity is not considered to be interconnected. However, the presence of connections between spacer particles means that reference cannot be made to a specific pore size. Furthermore, the mechanical properties improve as the spacer particle size reduces ${ }^{11}$ because this size reduction enables a better distribution of the matrix powder and compacting pressure, as shown in Fig. 1.

\section{Resistance to bending and compression}

The compression results confirm observations made in previous works ${ }^{11}$ and demonstrate the great importance of the amount of time that passes between compacting and removal of the spacer, with long delays causing weakening. Consequently, results with brittle fracture in the test specimens have been discarded.

As with resistance to bending, ${ }^{11}$ the most influential variables for resistance to compression are the addition of spacer and compacting pressure. The size of spacer particles and the thermal cycle are less influential. The effect of pressure depends on the amount of spacer added. Therefore, bending strength generally increases in the compacting pressure when the bicarbonate content is low $(<25$ vol. $\%)$ and weakens when more bicarbonate is added. ${ }^{11}$ In contrast, compression only increases strength in the compacting pressure with pieces that did not contain spacer (Fig. 2).

As shown in Table 1, for the same process parameters, resistance to bending is greater than resistance to compression. Although no significant differences between the relative density of the bending and compression test pieces were apparent, the size of the compression test specimens $(13.25 \mathrm{~cm}$ compared to

Table $1 \sigma_{\mathrm{y}}$ for bending and compression relative to volume per centage and spacer particle size, MPa

\begin{tabular}{|c|c|c|c|c|}
\hline \multirow[b]{2}{*}{ (Ti-6Al-4V)-spacer, vol.-\% } & \multirow[b]{2}{*}{ Stress } & \multicolumn{3}{|c|}{ Granule size, $\mu \mathrm{m}$} \\
\hline & & $125-250$ & $250-500$ & $500-1000$ \\
\hline $100-0$ & $\begin{array}{l}\text { Bending } \\
\text { Compression }\end{array}$ & $\begin{array}{l}1857 \pm 157 \\
1030 \pm 40\end{array}$ & & \\
\hline $75-25$ & $\begin{array}{l}\text { Bending } \\
\text { Compression }\end{array}$ & $\begin{array}{l}\text { No test pieces } \\
\text { No test pieces }\end{array}$ & $\begin{array}{l}535 \pm 110 \\
203 \pm 20\end{array}$ & $\begin{array}{l}500 \pm 40 * \\
192 \pm 10 *\end{array}$ \\
\hline $60-40$ & $\begin{array}{l}\text { Bending } \\
\text { Compression }\end{array}$ & $\begin{array}{l}283 \pm 33 \\
109 \pm 13\end{array}$ & $230 \pm 50$ & $\begin{array}{l}275 \pm 5 * \\
91 \pm 10 *\end{array}$ \\
\hline $45-55$ & $\begin{array}{l}\text { Bending } \\
\text { Compression }\end{array}$ & $\begin{array}{l}103 \pm 7 * \\
92 \pm 7 *\end{array}$ & & $\begin{array}{l}\text { No test pieces } \\
\text { No test pieces }\end{array}$ \\
\hline
\end{tabular}

*Results eliminated where the test piece showed brittle fracture. 


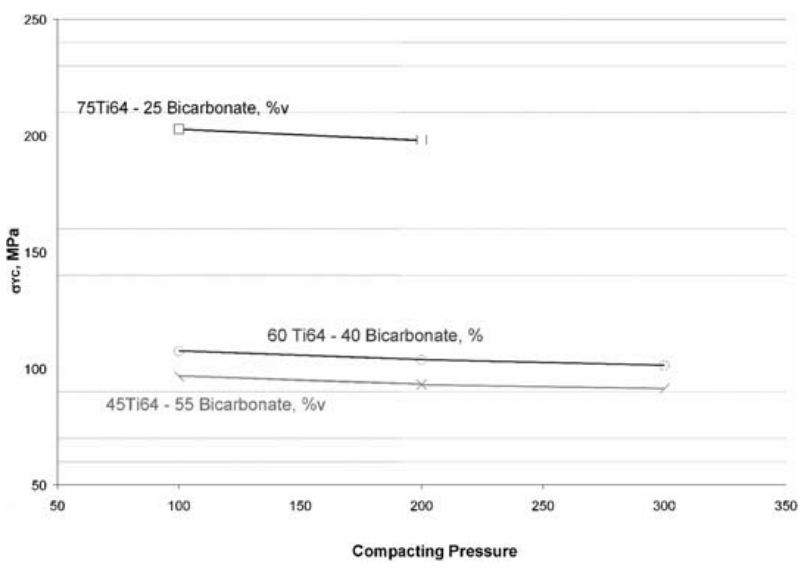

2 Compressive strength as function of compaction pressure for samples with different amounts of bicarbonate

$2 \cdot 3 \mathrm{~cm}$ for the bending test specimens) and the high speed of compacting mean that the pressure gradient is higher in the compression test specimen. This results in greater heterogeneity, and therefore, weaker areas exist in which plastic deformation can begin. Similarly, strength generally decreases as spacer size increases, and this is caused by a less homogeneous distribution of the powder matrix and applied pressure.

Moreover, scattering in the results is also greater for bending than compression, and this scattering is more pronounced as strength increases. This is due to the greater influence of the more fragile areas, caused by the spacer particles, ${ }^{11}$ when subjected to tensile stress and/or greater force. Similarly, results are generally more scattered when particle sizes are smaller, implying an increased area of contact with the powder matrix.

Since the compressive yield strength of cortical bone is between 110 and $200 \mathrm{MPa}$, with a lower value for bending, $3,13,14$ only specimens with 25 vol.- $\%$ of spacer can be safely used as a substitute for human cortical bone. Higher levels of spacer result in inadequate compressive strength.

The level of strength obtained is related to the relative density of the pieces according to the model (equation (1)) proposed by Gibson and Ashby ${ }^{15}$ and based on the average strength of pieces with the same bicarbonate volume (this being the most influential variable)

$$
\frac{\sigma_{\mathrm{Y}}}{\sigma_{\mathrm{S}}}=C\left(\frac{\rho *}{\rho_{\mathrm{S}}}\right)^{\mathrm{n}}
$$

where the constants $C$ and $n$ reflect foam parameters such as cell morphology, shape and arrangement of the pores. $^{16,17}$

Although the model was proposed for foams $\left(\rho_{\mathrm{r}}<0 \cdot 3\right)$ with an ideal microstructure, ${ }^{15}$ a good correlation has been found $\left(R^{2}=0.99\right)$ between the relative density of

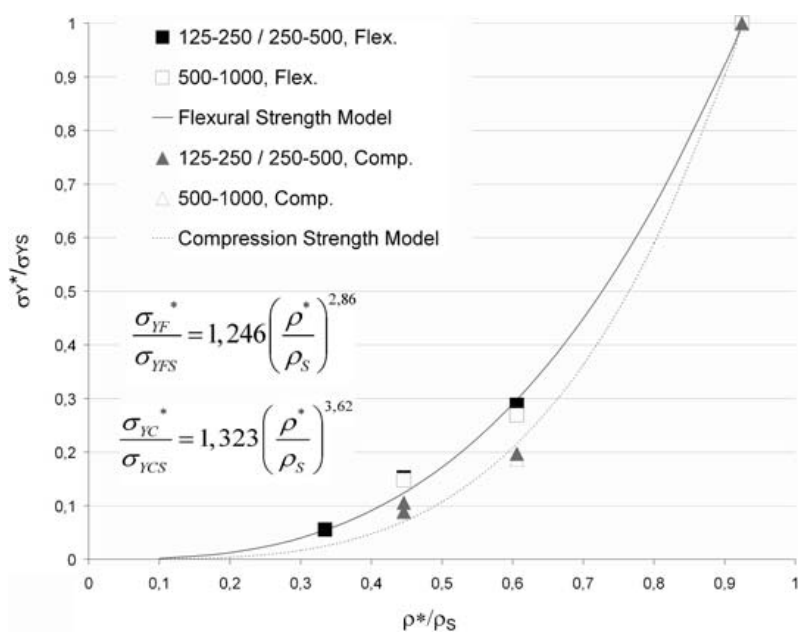

3 Relative resistance to bending and compression according to relative density (adjusted for developed models)

porous specimens obtained $\left(\rho_{\mathrm{r}}=\rho^{*} / \rho_{\mathrm{S}}\right)$ and their relative resistance to bending $\left(\sigma_{\mathrm{YFr}}=\sigma_{\mathrm{YF}}^{*} / \sigma_{\mathrm{YFS}}\right)$ and compression $\left(\sigma_{\mathrm{YCr}}=\sigma_{\mathrm{YC}}^{*} / \sigma_{\mathrm{YCS}}\right)$. (Fig. 3).

It should be noted that, in accordance with observations made during the production process, the mechanical properties of the developed porous specimens can be optimised using the lowest possible compacting pressure. This facilitates a more uniform distribution and the elimination of spacer particles. Lower compacting pressure also facilitates slower compacting, and this helps consolidation by reducing the elastic recovery of the material.

\section{Stiffness}

The stiffness of the porous pieces developed depends primarily on the addition of spacer. No significant differences related to the other process parameters $(T, t$, $P$ and spacer size) were found.

In the same way as for strength, models were obtained correlating stiffness with the relative density of the developed specimens. Table 2 lists the coefficients obtained for the porous specimens developed in this work as well as TiCP3 porous specimens produced in a previous research ${ }^{9}$ and results published by other authors using the spacer method to develop porous Ti.

In Table 2, the correlation model of relative stiffness and bending is shown independently of the measuring method used (curve slope or formula) for the Ti-6Al-4V specimens developed in this work. The stiffness and compression model obtained is very similar to those proposed by Gibson and Ashby ${ }^{15}$ and Bram et al. ${ }^{10}$ This is due to similarities in the development of the pieces and measuring methods. In contrast, Esen and Bor ${ }^{17}$ used spherical particles of Ti so that the walls created between

Table 2 Correlation models based on relative stiffness and relative density

\begin{tabular}{|c|c|c|c|c|c|}
\hline Material & Test & Stiffness measurement & $C$ & $n$ & Correlation model $R^{2}$ \\
\hline TiCP3 & Bending & Curve slope 9 & $1 \cdot 037$ & $1 \cdot 62$ & 0.86 \\
\hline Ti-6Al-4V & Bending & Curve slope & $1 \cdot 172$ & $1 \cdot 60$ & 0.97 \\
\hline Ti-6Al-4V & Bending & Formula & $1 \cdot 173$ & $1 \cdot 60$ & 0.98 \\
\hline Ti-6Al-4V & Compression & Curve slope & $1 \cdot 136$ & $2 \cdot 19$ & 0.96 \\
\hline Ideal foam & & Gibson and Ashby ${ }^{15}$ & $1 \cdot 000$ & $2 \cdot 00$ & $\ldots$ \\
\hline TiCP & Compression & Bram et al. ${ }^{10}$ & 0.167 & $2 \cdot 00$ & $\ldots$ \\
\hline $\mathrm{TiCP}$ & Compression & Esen and Bor ${ }^{17}$ & 1.598 & $4 \cdot 72$ & 0.99 \\
\hline
\end{tabular}




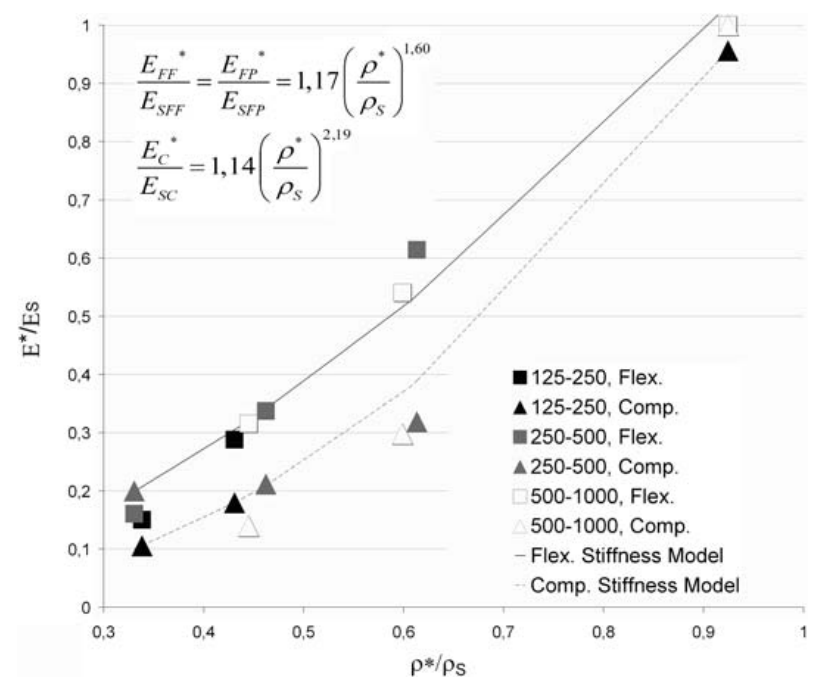

4 Relative stiffness and compression according to relative density (adjusted for developed models)

the macropores during sintering were smaller and demonstrated an apparently reduced cohesion. This explains why his model is more sensitive to variations in relative density. Moreover, the value close to unity obtained for the coefficient $C$ in our models is consistent because, when the relative density is near to one, then the relative stiffness should also be near to one. Finally, it is worth emphasising the small difference in coefficient $C$ obtained for porous TiCP specimens and Ti-6Al-4V ones. The lower value for the first samples is due to lower levels of alloying elements. ${ }^{18,19}$

Figure 4 shows the correlation between the models obtained for the Ti-6Al-4V specimens developed in this work and the experimental values. As with strength, the relative stiffness is higher for bending than for compression. This is related to the greater cohesion and homogeneity for the pieces obtained. Therefore, the smaller size of the bending specimens results in a more uniform pressure distribution and less elastic recovery during compacting, and this leads to a greater cohesion and stiffness. As shown in Fig. 4, for pieces with a 25 vol. $\%$ spacer $\left(\rho_{\mathrm{r}} \approx 0 \cdot 4\right)$, the degree of stiffness is reduced by $\sim 50 \%$ when compared with the solid material. This improves behaviour when placed alongside human cortical bone and so reduces bone resorption problems.

\section{Conclusions}

The spacing method has enabled the development of less rigid porous $\mathrm{Ti}-6 \mathrm{Al}-4 \mathrm{~V}$ specimens with a flexural and compressive strength that makes the material suitable for use as bone substitute. The porosity of the developed materials increases when spacer is added, and while the spacer particles are not completely connected, there is some interconnection.

The parameters that most influence the mechanical properties are the addition of spacer and compacting pressure. By contrast, there is no significant variation of properties depending on the thermal cycle, so sintering should be carried out at $1275^{\circ} \mathrm{C}$ for $2 \mathrm{~h}$, which allows sintering and enables a reduction in the consumed energy compared to the rest of thermal cycles used.

Obtained properties are slightly higher by reducing the particle size of the spacer. However, the compressive strength of human cortical bone only can be achieved with 25 vol.- $\%$ of ammonium bicarbonate at the most. These specimens are about half as stiff as the bulk material, and this improves their behaviour alongside bone and reduces problems of weakening.

The mathematical models obtained enable estimates to be made of the mechanical properties produced (resistance to bending, compression and stiffness) as a function of relative density or the addition of spacer.

\section{Acknowledgements}

The authors wish to thank the Spanish Ministry of Science and Innovation for the support received under project no. PET2008_0158_02. The translation of this article was funded by the Universidad Politécnica de Valencia.

\section{References}

1. G. Ryan, A. Pandit and D. P. Apatsidis: Biomaterials, 2006, 27, 2651-2670.

2. in 'ASM handbook', Vol. 2, 'Properties and selection: nonferrous alloys and special-purpose materials', 1170; 1990, Materials Park, $\mathrm{OH}, \mathrm{ASM}$ International.

3. K. Asaoka and M. Kon: Mater. Sci. Forum, 2003, 426-432, 30793084.

4. M. Niinomi: J. Mech. Behav. Biomed. Mater., 2008, 1, (1), 30-42.

5. L. Reig, V. Amigó, D. Busquets, M. D. Salvador and J. A. Calero: Rev. Metall., to be published.

6. H. J. Rack and J. I. Qazi: Mater. Sci. Eng. C, 2006, C26, (8), 1269 277.

7. G. Kotan and A. S. Bor: Turk. J. Eng. Environ. Sci., 2007, 31, 149156.

8. M. Köhl, M. Bram, H. P. Buckremer and D. Stöver: Proc. Conf. Euro PM2007, Toulouse, France, October 2007, European Powder Metallurgy Association, 129-134

9. V. Amigó, L. Reig, D. J. Busquets, J. L. Ortiz and J. A. Calero: Powder Metall., to be published.

10. M. Bram, S. H. Bogdanski, M. Koller, H. P. Buchkremer and D. Stover: Proc. Conf. Euro PM2005, Prague, Czech Republic, October 2005, European Powder Metallurgy Association, 517-522.

11. L. Reig, V. Amigó, D. Busquets, M. D. Salvador and J. A. Calero: Proc. Conf. Sintering 2008, La Jolla, CA, USA, November 2008, American Ceramic Society.

12. H. P. Degischer and B. Kriszt: 'Handbook of cellular metals: production, processing, applications', 22-184; 2002, Weinheim, Wiley-VCH.

13. M. Comín, J. L. Peris, J. M. Prat, J. R. Decoz, P. M. Vera and J. V: Hoyos: 'Biomecánica de la fractura ósea y técnicas de reparación', 66-69; 1999, Valencia, Publicaciones UPV.

14. R. B. Heimann: $C M U J$., 2002, 1, 23-46.

15. L. J. Gibson and M. F. Ashby: 'Cellular solids: structure and properties', 175-231; 1999, Cambridge, Cambridge University Press.

16. M. Ashby, E. Michael, F. Tony, N. A. Gibson, L. J. Hutchinson and J. W. Wadley: 'Metal foams: a design guide', 6-54; 2000, Oxford, Butterworth-Heinemann.

17. Z. Esen and S. Bor: Scr. Mater., 2007, 56, (5), 341-344.

18. C. Leyens and M. Peters: 'Titanium and titanium alloys. Fundamentals and applications', 1-35; 2003, Weinheim, Wiley$\mathrm{VCH}$.

19. G. Lütjering and J. C. Williams: 'Titanium', 2nd edn, 13-51; 2007, Berlin, Springer, Engineering Materials and Processes. 


\section{Authors Queries}

Journal: Powder Metallurgy

Paper: 1628

Title: Stiffness variation of porous titanium developed using space holder method

Dear Author

During the preparation of your manuscript for publication, the questions listed below have arisen. Please attend to these matters and return this form with your proof. Many thanks for your assistance

\begin{tabular}{|l|l|l|}
\hline $\begin{array}{l}\text { Query } \\
\text { Reference }\end{array}$ & Query & Remarks \\
\hline 1 & $\begin{array}{l}\text { Author: Please confirm the run- } \\
\text { ning head. }\end{array}$ & \\
\hline 2 & $\begin{array}{l}\text { Author: Please check the edits } \\
\text { made in this sentence. }\end{array}$ & \\
\hline 3 & $\begin{array}{l}\text { Author: The reference list was } \\
\text { reordered so that citations are } \\
\text { now in sequence. }\end{array}$ & \\
\hline 4 & $\begin{array}{l}\text { Author: Please update the infor- } \\
\text { mation. }\end{array}$ & \\
\hline 5 & Author: Please update the info. & \\
\hline 6 & $\begin{array}{l}\text { Author: Please provide page/ } \\
\text { paper number. }\end{array}$ & \\
\hline
\end{tabular}

